\title{
PREDICTABILITY OF PSYCHIC OUTCOME FOR EXERCISE TRAINING AND EXERCISE TRAINING INCLUDING RELAXATION THERAPY AFTER MYOCARDIAL INFARCTION
}

\author{
H. J. Duivenvoorden* and J. van Dixhoorn ${ }^{*}+$
}

(Received 4 September 1990; accepted in revised form 16 January 1991)

\begin{abstract}
Predictability of the psychic outcome for two cardiac rehabilitation programmes was investigated in 119 myocardial infarction patients. They were randomly assigned to either a five-week daily exercise training or to an identical training in combination with six sessions of relaxation therapy, individually. The psychic outcome was constructed as a composite measure of change on six psychological questionnaires. The aim was to determine the predictive qualities of base-line: (1) clinical data; (2) exercise testing; (3) psychosocial information derived from interview; and (4) validated psychological questionnaires and whether the kind of rehabilitation programme has any influence on the predictive qualities of the variables.

The psychic outcome turned out to be highly predictable (multiple correlation of 0.72 ). Predictors of relatively high importance were age, work-status and job-level, followed by mild heart failure, diastolic blood pressure and heart rate, all of them dependent upon the kind of treatment. It implies that the type of rehabilitation programme modified the effect of the determinants of psychic outcome.

This research strategy is promising and deserves to be stimulated in order to build rehabilitation programmes tailored to the needs and abilities of the individual patient.
\end{abstract}

\section{INTRODUCTION}

SEVERAL studies have dealt with determinants of outcome of the recovery process after myocardial infarction, with respect to emotional and social endpoints [1-5]. The aim of this study is to investigate predictability of psychic outcome after having participated in a cardiac rehabilitation programme. The outcome is composed of changes on six questionnaires, completed before and after rehabilitation. The question is what patients improve after rehabilitation and what patients do not or even deteriorate. To date, research studies have failed to substantiate the high expectation of the psychological benefit of rehabilitation [6]. One explanation is that rehabilitation is effective for a limited percentage of myocardial infarction patients [7]. A successful prediction of the outcome will make it possible to assign optimally patients to rehabilitation, in order to avoid possible harmful effects $[6,8]$, save unnecessary time and effort, and raise the efficacy of a programme [9].

In this study the predictability of psychic improvement is investigated for two rehabilitation programmes, consisting of physical reconditioning exercises and of individual relaxation therapy added to physical exercise. Relaxation therapy has shown to have psychological benefits [10], although the effect was moderate. Possibly, a combined treatment is beneficial to some patients, whereas simple physical exercises may be sufficient or even preferable to others.

The main questions to be studied are, whether psychic outcome is predictable on

*Erasmus University Rotterdam, P.O. Box 1738, Rotterdam, The Netherlands.

† St Joannes de Deo Hospital, P.O. Box 1638 Haarlem, The Netherlands.

¥Author to whom correspondence should be addressed at: F. van Blankenheimstraat 10, 3817 AG Amersfoort, The Netherlands.

Supported by a grant from the Dutch Heart Foundation. 
the basis of initial medical, psychosocial and exercise data, and whether the kind of rehabilitation programme has any influence on the predictive qualities of the variables.

\section{PATIENTS AND METHODS}

\section{Patients}

After discharge from various hospitals, cardiac patients are referred to the regional rehabilitation centre at St Joannes de Deo Hospital, Haarlem, The Netherlands. A total of 156 myocardial infarction (MI) patients were admitted to the study. They were randomly allocated to one out of two treatment protocols. Patients who were in need of individual (psychosocial) help received relaxation therapy. As a consequence, they could not be randomized and had to be excluded from the study. There were no age limits. Nine women were referred for rehabilitation. For 37 patients information on psychic outcome was either unavailable or incomplete. Thus, the data on 119 patients were used in the analysis.

\section{Procedure}

Clinical base-line data and medical history were obtained from information of the referring cardiologist. At entry, patients were interviewed to obtain psychosocial information and were asked to participate in the study. After informed consent, they completed additional psychological questionnaires. The questionnaires were again administered after the patient completed the programme. All patients participated in a physical reconditioning programme. In addition, half of them were randomly allocated to individual relaxation therapy. Graded exercise testing was performed on a bicycle ergometer before and after physical training.

\section{Clinical data}

Information on infarction size, site and complications were derived from hospital records. An infarction was classified as small when serum glutamic-oxaloacetic transaminase (SGOT) was elevated but remained below $60 \mathrm{U} / \mathrm{I}$, whereas SGOT levels above $120 \mathrm{U} / \mathrm{I}$ indicated a large infarction.

In-hospital occurrence of hypotension, a cardiothoracic radio $>50 \%$ or pulmonary congestion were taken as signs of (mild) heart failure. Also, data were noted concerning a previous infarction, coronary bypass surgery, and angina pectoris of longer duration than one month before infarction, as well as on the presence of angina at discharge and the use of cardiac drugs before infarction or at discharge. In addition, information on hypertension and smoking habits before infarction was gained.

\section{Psychosocial interview}

The patient was interviewed, partly also on the clinical data, particularly regarding the pre-infarction period (smoking, hypertension). Work situation and job level were noted. Job level was ranked as follows: manual unskilled, manual skilled labourers, lower level white collar workers, independent, intermediate and high level white collar workers. The patient was asked about his feelings of pain during the infarction and his attribution of the cause of the infarction. Moreover, the interviewer rated the presence of psychosocial stress in the life situation of the patient.

\section{Psychological questionnaires}

They were described in detail elsewhere [10]. In short, (1) Heart Patients Psychological Questionnaire [11], to measure the well-being of cardiac patients in three scales: (a) Well-being, (b) Subjective invalidity, (c) Displeasure. (2) Anxiety measured by STAI in two modes: state and trait anxiety [12]. (3) Slceping habits, consisting of questions about hours of sleep, daytime nap and sleep quality [13]. (4) Functional symptoms, consisting of physical complaints, not typical of angina pectoris. In addition, two questionnaires referred to the pre-infarction period: (5) Jenkins Activity Scale (JAS), for Type A behaviour [14], and (6) Maastricht Questionnaire, for vital exhaustion and depression [15].

\section{Exercise testing}

After an adaptation period on the bicycle, the test was started with a $1-$ min period of cycling at 60 cycles a minute without load, and for two minutes at 60 Watts. The test was continued by increasing the workload by 30 Watts every two minutes until symptoms prevented the patient from continuing or until the physician terminated the test. The occurrence of exercise-induced angina pectoris, STabnormalities and arrhythmias were noted. The ST-abnormalities were mostly ST-depressions of $2 \mathrm{~mm}$ or more, horizontal or downsloping. Arrhythmias were coded as single premature ventricular complexes, or as complex (groups or runs of multifocal or frequent premature ventricular complexes, bigeminy or ventircular tachycardia). A bipolar ECG lead (CM5) was taken during the half minute before the workload was increased. Blood pressure was taken before the test and at maximum workload. 


\section{Rehabilitation}

Rehabilitation consisted of a programme of either exercise training plus relaxation training or of exercise training alone. Exercise training consisted of five weeks of interval training, once a day for half an hour, on a bicycle ergometer. Training was given in groups of four patients supervised by two physical therapists. Each patient was exercised up to $70 \%$ of the peak heart rate attained at pre-training exercise testing. Relaxation training was given once a week in six individual sessions of $1 \mathrm{hr}$ each, by five trained therapists. Three of them were psychologists, one a medical doctor and one a physical therapist. They did not participate in the exercise programme. Several procedures for active and passive relaxation were applied, centring around a respiratory technique. This is described in detail elsewhere [16]. In short, EMG feedback of the frontalis muscle is used for muscle relaxation and for monitoring unnecessary inspiratory effort. The patient learned to observe and elicit a 'shift' in the respiratory pattern, such that inspiration expanded both the lower abdomen and the costal margin, expiration was moderated and slow. Manual technique was applied to elicit breathing movements involving the trunk as a whole and requiring less effort. This was practised first in the supine position to induce 'passive relaxation', but later also sitting up and standing ('active relaxation'). The patient was asked to practise daily at home and to use the technique in the event of any chest discomfort. Care was taken to introduce relaxation as an ingredient of the routine rehabilitation procedure, rather than psychological help. The treatment itself was presented without any bias: emphasizing the technical and physical aspects of relaxation, its utility in dealing with daily stress, and providing a rationale in the form of the biofeedback instrumentation and breathing 'exercises'. The therapists, however, were aware that this was a strategy to facilitate possible psychotherapeutic implications of the treatment.

\section{Outcome criterion}

In order to obtain a single measure, indicating the psychic outcome after rehabilitation, six psychological questionnaires were integrated into a composite change score: one set represented psychic aspects and consisted of Anxiety State and Trait and Displeasure, another set represented somatic aspects, consisting of Subjective invalidity, Sleep quality and Functional complaints. In order to correct for the influence of the initial value, pre-post changes were expressed as a percentage of their possible change, which is the difference between the initial score and theoretically the minimum score in the case of a decrease and the maximum score in the case of an increase. The overall outcome was construed as the average of the two sets.

\section{Statistical analysis}

In order to investigate the predictive qualities of 'baseline' factors the method of multiple regression analysis was applied. To get an insight into the relative importance of variables in predicting the psychic outcome, the standardized regression coefficient $(B)$ is convenient. The $p$-values indicate the level of significance of the pertinent regression coefficients. They were calculated for all predictor variables individually, as well as for four sets of variables: clinical, interview, exercise data and psychological questionnaires. The multiple correlation coefficient (MR) is the Pearson product-moment correlation coefficient between the set of predictor variables on the one hand and the outcome variable on the other; the corresponding $F$-value indicates whether the MR is statistically significant. The MR squared (sometimes called co-efficient of determination) indicates the percentage of explained variance, identical to the meaning of the Pearson correlation squared. In order to determine the influence of the treatment form, the joint treatment was coded as 1 and exercise training as 2, and interaction terms were constructed, consisting of each predictor variable times treatment form. Thus, the sets consisted of the relevant predictor variables and their respective interaction terms.

The procedure was as follows: first, all variables pertaining to one set were entered into the regression equation, after which the variables not meeting the criterion for removal $(p<0.10)$, were estimated one by one. Next, in order to get an insight into the differential qualities of the four sets jointly, all variables selected in one of the foregoing four sets of regression, were entered into the final regression analysis, meeting the same level of removal.

\section{RESULTS}

A total of 156 myocardial infarction patients were admitted to the study. Their base-line characteristics have been presented in a previous paper [10]. Out of them 17 patients dropped out of the programme. Moreover, psychological questionnaires were not always completed. Thus, the composite score for psychic improvement could be calculated only for 119 patients and the prediction analysis had to be limited 
to thesc patients. There wcre no differences between the treatments. A comparison with the base-line of the total study population, did not reveal significant differences.

On average, psychological questionnaires did not show a change after exercise training. However, anxiety state and subjective invalidity decreased whereas wellbeing increased for patients receiving the treatments jointly. The difference between treatments was significant for well-being [10].

\section{Prediction analysis}

Differential qualities of the variables individually. Of the clinical variables mild heart failure $(B=0.19)$ and cardiac history $(B=-0.18)$ turned out to be relevant to psychic change after rehabilitation (see Table I).

\begin{tabular}{|c|c|c|}
\hline Predictor variables & $\begin{array}{c}B \\
\text { (Standardized) }\end{array}$ & $p$ \\
\hline Treatment & -0.02 & 0.86 \\
\hline $\begin{array}{l}\text { Clinical } \\
\text { Sex (1) } \\
\text { Age } \\
\text { Hypertension (pre) (2) } \\
\text { Smoking (3) } \\
\text { Angina pectoris (pre) (4) } \\
\text { Cardiac history (5) } \\
\text { Beta-blockers (pre) (2) } \\
\text { Diuretics (pre) (2) } \\
\text { Infarction size (6) } \\
\text { Mild heart failure (2) } \\
\text { Cardiac drugs (7) } \\
\text { Beta-blockers (2) } \\
\text { Angina pectoris (8) }\end{array}$ & $\begin{array}{r}-0.03 \\
0.11 \\
-0.11 \\
0.04 \\
0.03 \\
-0.18 \\
-0.10 \\
-0.02 \\
0.05 \\
0.19 \\
0.04 \\
-0.04 \\
-0.04\end{array}$ & $\begin{array}{l}0.79 \\
0.21 \\
0.22 \\
0.69 \\
0.75 \\
0.06 \\
0.26 \\
0.86 \\
0.61 \\
0.04 \\
0.64 \\
0.63 \\
0.68\end{array}$ \\
\hline $\begin{array}{l}\text { Interview } \\
\text { Work status (9) } \\
\text { Level of job (10) } \\
\text { Infarction pain (11) } \\
\text { Cause MI: stress (2) } \\
\text { Cause MI: external (2) } \\
\text { Cause MI: risk factors (2) } \\
\text { Cause MI: psychic (2) } \\
\text { Psychosocial stress (12) }\end{array}$ & $\begin{array}{r}0.22 \\
0.00 \\
-0.08 \\
-0.08 \\
-0.10 \\
0.19 \\
-0.28 \\
-0.08\end{array}$ & $\begin{array}{l}0.02 \\
0.97 \\
0.36 \\
0.40 \\
0.28 \\
0.04 \\
0.00 \\
0.40\end{array}$ \\
\hline $\begin{array}{l}\text { Exercise testing } \\
\text { Maximum workload } \\
\text { Work capacity (\%) } \\
\text { Heart rate (maximal } \\
\text { Heart rate (resting) } \\
\text { Heart rate (Watt = 60) } \\
\text { Diastolic BP (resting) } \\
\text { Systolic BP (resting) } \\
\text { Systolic BP (maximum) } \\
\text { Systolic BP (rise) } \\
\text { ECG-abnormalities (13) }\end{array}$ & $\begin{array}{r}-0.14 \\
-0.10 \\
-0.11 \\
0.11 \\
0.07 \\
-0.22 \\
-0.12 \\
-0.15 \\
-0.06 \\
0.05\end{array}$ & $\begin{array}{l}0.14 \\
0.27 \\
0.23 \\
0.25 \\
0.44 \\
0.02 \\
0.18 \\
0.11 \\
0.48 \\
0.56\end{array}$ \\
\hline
\end{tabular}

(Continued). 
TABLE I. - Continued

\begin{tabular}{lcc}
\hline Predictor variables & $\begin{array}{c}B \\
\text { (Standardized) }\end{array}$ & $p$ \\
\hline Psychological questionnaires & & \\
Sleep quality & 0.17 & 0.06 \\
Daytime nap (14) & 0.09 & 0.36 \\
Vital exhaustion (pre) & -0.24 & 0.01 \\
Type A behaviour (pre) & -0.02 & 0.87 \\
Functional complaints & -0.30 & 0.00 \\
Wellbeing & 0.16 & 0.08 \\
Subjective invalidity & -0.19 & 0.04 \\
Displeasure & -0.02 & 0.80 \\
Anxiety (state) & -0.11 & 0.23 \\
Anxiety (trait) & -0.14 & 0.12 \\
\hline
\end{tabular}

Treatment: exercise + relaxation $=1$, exercise only $=2$; BP: blood pressure. (1) Male $=1$, female $=2$; (2) present $=1$, absent $=$ 0 ; (3) number of cigarettes; (4) anginal complaints or anti-anginal drugs $=1$, else $=0 ;(5)$ previous infarction or coronary bypass surgery $=1$, else $=0 ;(6)$ small $=1$, medium $=2$, large $=3 ;(7)$ heart glucosides or diuretics or anti-arrhythmic drugs $=1$, clse $=0$; (8) anginal complaints at hospital discharge or anti-anginal drugs or exercise-induced chest pain $=1$, else $=0$; (9) fulltime $=1$, parttime $=2$, none $=3 ;(10)$ low level $=1$, high level $=6$ (see methods section); (11) severe $=1$, moderate $=2$, hardly or none $=3$; (12) much $=1$, moderate $=2$, hardly $=3 ;$ (13) exercise induced STabnormalities or arrhythmias $=1$, else $=0$; (14) quarter of hours.

From the interview data the cause of the infarction as perceived by the patient had predictive power. Patients who attributed the MI to emotional factors did not improve much psychologically $(B=-0.28)$, while those who attributed their MI to risk factors did $(B=0.19)$. Also, work status had predictive power $(B=0.22)$. Unexpectedly, those who had a job improved less than those without work.

Of the exercise variables only resting diastolic blood pressure reached statistical significance: patients with high diastolic blood pressure improved relatively less $(B=-0.22)$.

The psychological variables were of material importance. Five variables contributed to estimating psychic outcome. Of paramount importance appeared to be functional complaints $(B=-0.30)$, followed by vital exhaustion before $\mathrm{MI}(B=$ $-0.24)$ and subjective invalidity $(B=-0.19)$ : the higher the initial score, indicating more complaints, the lower improvement. Sleep quality $(B=0.17)$ and well-being $(B=0.16)$ were also associated, although only marginally significant. Patients who slept or felt relatively well initially, improved more after rehabilitation.

Differential qualities of the four sets of variables individually. The performance of clinical variables jointly is to be considered moderate $(M R=0.35)$. Treatment condition in interaction with age $(B=1.46)$ contributed highest, followed by treatment condition $(B=-1.18)$. This indicated that older patients benefit more from exercise training than those who are younger; and, vice versa, relatively young patients benefit from exercise training and relaxation therapy jointly more than the other patients. The contribution of treatment condition of the prediction implied that the effect of exercise training solely was less positive than that of exercise training combined with relaxation therapy (see Table II). 
TABLE II. - MULTIPLE REGRESSION ANALYSES FOR PSYCHIC OUTCOME, FOUR SETS SEPARATELY

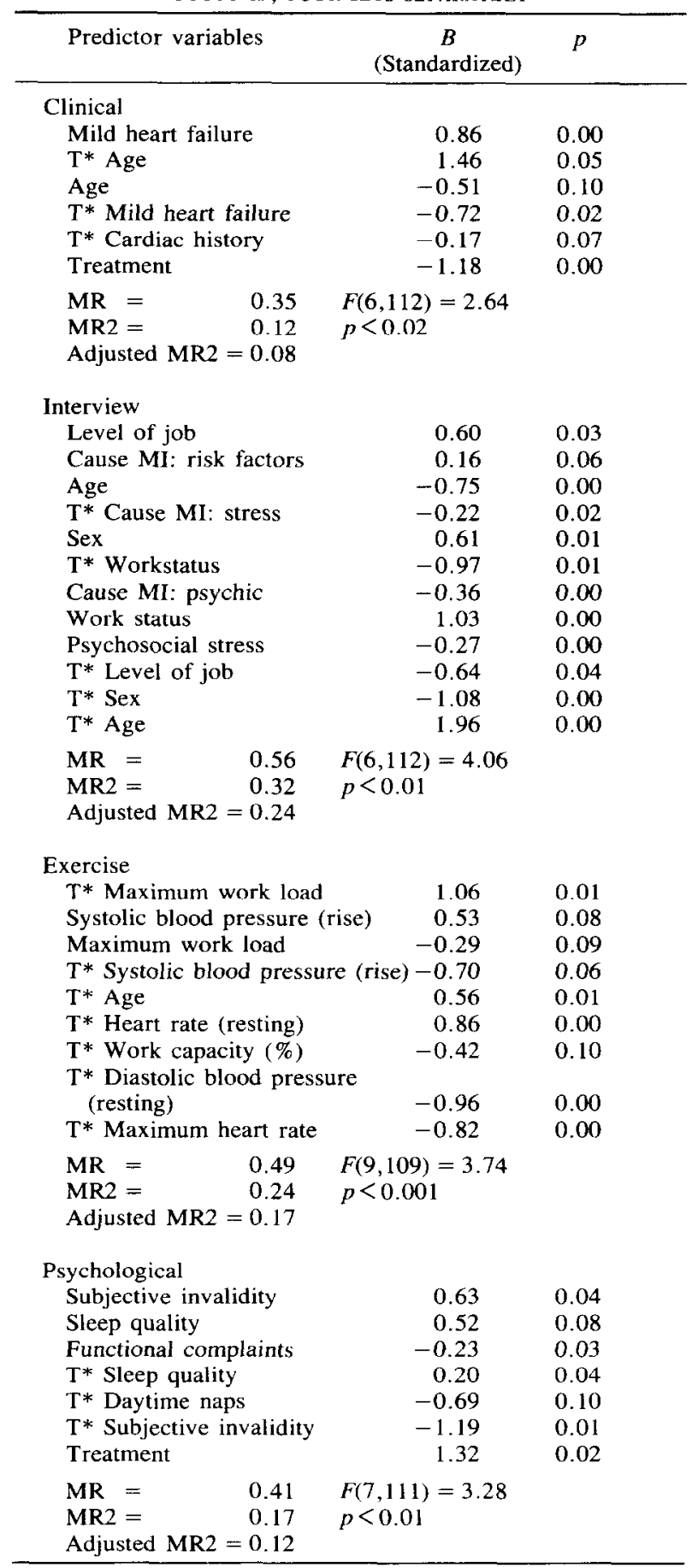

$T=$ treatment. Variable values: see Table $\mathrm{I}$. 
The performance of the interview variables was the highest of all sets $(\mathrm{MR}=$ 0.56). Table II shows that sex, age and work status were of high relevance, mostly even of higher relevance when combined with treatment. It is worth mentioning that $\operatorname{sex}(B=0.61)$ was positively related with psychic outcome, while sex in interaction with treatment $(B=1.08)$ was negatively related. It means that on average women benefit more than men, unless they only participated in exercise training. Similarly, the association of work status with psychic outcome was positive $(B=1.03)$ and reversed of direction when treatment condition was taken into account $(B=0.97)$. It means that on average patients who were unemployed improved more, but if treatment form is taken into account, patients with jobs improved more when they underwent comprehensive rehabilitation. The relationship of age was the same as in the set of clinical variables. It was inversely related to outcome $(B=0.75)$, whereas in interaction with treatment the association yielded a highly positive value $(B=1.96)$.

The performance of exercise variables jointly turned out to be of moderate level $(\mathrm{MR}=0.49)$. In complete line with the performance of the previous sets, treatment in interaction with the haseline measurements derived from exercise testing reached a high level of differential qualities, compared to variables without interaction. A relatively high level of importance was treatment in interaction with maximum workload $(B=1.06)$ : patients with a high level of initial fitness had a high level of improvement when exercise training was the sole treatment. The bivariate relationship of resting diastolic blood pressure was strengthened when treatment was taken into account $(B=-0.96)$ : high initial blood pressure was particularly unfavourable for psychic outcome when exercise was the sole treatment. On the other hand, a high resting heart rate was relatively favourable for patients who only participated in exercise training $(B=0.86)$.

The performance of the psychological variables jointly was moderate $(\mathrm{MR}=$ $0.41)$. Of this set of variables treatment $(=1.32)$ appeared to be of highest weight, closely followed by the interaction of treatment with subjective invalidity $(B=-1.19)$. Also of interest were daytime naps in interaction with treatment $(B=-0.69)$ and sleep quality $(B=0.52)$.

Differential qualities of the variables jointly. The performance of the four sets of variables jointly turned out to be $(M R=0.72)$, which has to be valued as high (see Table III).

From the analysis of the variables selected in any of the foregoing four sets it appeared that ultimately age, work status, and to a lesser degree, level of job, were relatively of high importance in predicting the psychic outcome. These variables contributed significantly to predicting the outcome, individually as well as in interaction with treatment. Although of lesser importance, several climical and exercise variables had differential power, for the greater part in interaction with treatment. Patients with a high resting diastolic blood pressure, and patients with a high maximal heart rate improved relatively less psychically, when exercise was the sole treatment. For resting heart rate, the nature of the association was reversed: patients with a high resting heart rate improved relatively more, when exercise training was the sole treatment. Interestingly, psychological variables, including the attribution of the genesis of MI by the patient, had the smallest predictive value. 


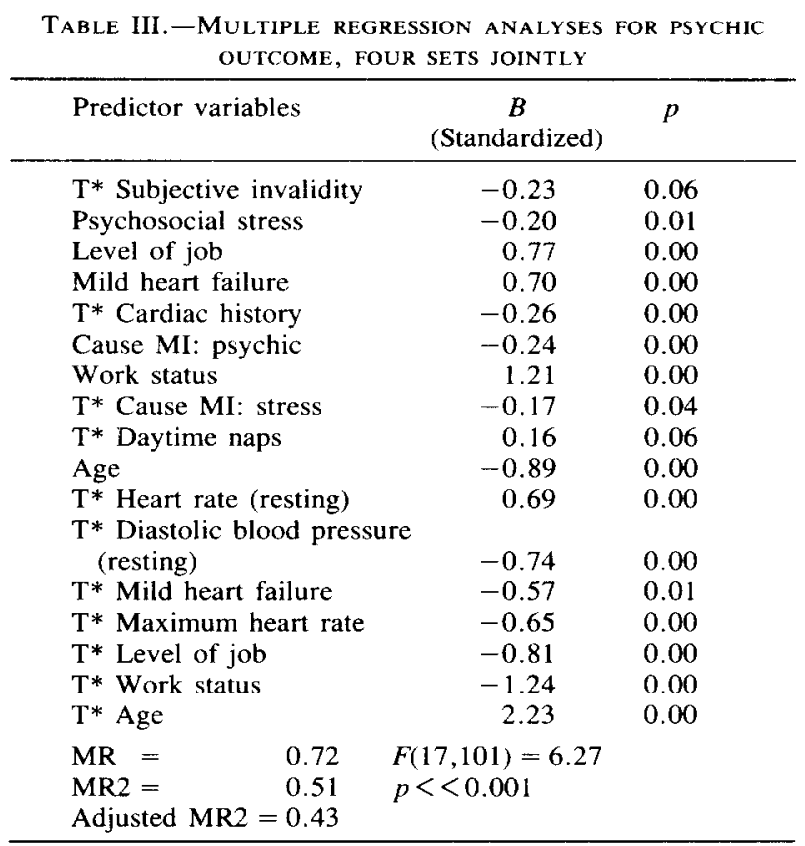

$\mathrm{T}=$ treatment. Variable values: see Table $\mathbf{I}$.

\section{DISCUSSION}

The psychological benefit after an early five-week rehabilitation programme was highly predictable on the basis of initial medical, exercise and psychosocial data. This finding is promising. If predictability remains high in case of replication, we are in principle able to construct a tool for assigning patients optimally to rehabilitation. It is of utmost importance to identify patients who will not benefit from a given treatment, e.g. exercise training, and who are at risk of psychological deterioration [1,3]. For them, other kinds of treatments will have to be devised and applied, tailored to the abilities and needs of the individual patient.

The most important predictors for psychic outcome were age, work status and job level. In the literature, age appears to be related to return to work $[4,5]$, but not to psychic outcome [19], often because rehabilitation is limited to younger patients [1]. There were no age limits for participation in this study. In some studies work status had a predictive value [19]; however, it is often not utilized [20, 21] or rehabilitation is limited to employed patients [5]. In this study, psychic benefit was greater on average for those who did not work.

Our special interest concerned the effect of the nature of rehabilitation. Two programmes were compared. Briefly, we added interaction terms consisting of the predictor variables times the kind of treatment. It appeared that the nature of the treatment influenced the effiects of the predictor variables materially. In the final analysis almost all selected variables were interaction terms. Only two variables were selected regardless of the kind of treatment. This result has two important implications: First, it implies that some patients had a more positive outcome with the one treatment (exercise training) and other patients with the comprehensive 
treatment (exercise training and individual relaxation therapy). Thus, the population of cardiac rehabilitation patients is not homogeneous with respect to suitability for different rehabilitation programmes. The second implication is therefore that group averages are not sufficient to assess the possible value of an intervention for a heterogeneous population. This may explain why research studies often showed only little psychosocial effect of cardiac rehabilitation [6]. Thus, the philosophy of 'tailor-made rehabilitation' found empirical support in this prediction analysis [18].

An example will clarify this point. Multiple regression analysis results in an equation that estimates the outcome measure, in this case psychic change. Using the variables selected in the final analysis, examples can be construed of patients with differing outcome estimates for the two treatments. For example: a person, 40 years of age, with a high job level, working full time with high psychosocial stress according to the interviewer, who feels strongly invalidated, had signs of mild heart failure in the hospital, and a history of previous infarction, coronary surgery or cardiac arrhythmias, attributes the infarction to stress, but not to emotional factors, takes little or no daytime naps, has a resting heart rate of $70 \mathrm{bpm}$, a diastolic blood pressure of 100 and a maximal heart rate of 160 . The estimated benefit of exercise training for this person is $\mathbf{1 5 . 6}$ whereas the estimated benefit of the joint treatments is 53.2. In other words, for such a person exercise as a single treatment falls short to a high degree. What kind of person would benefit more from exercise? A 60-year old manual worker, fully employed, with no feelings of invalidity, high psychosocial stress according to the interviewer, no signs of heart failure, nor a cardiac history, who does not attribute the infarction to emotional factors or stress, who takes daytime naps, has a resting heart rate of $80 \mathrm{bpm}$, a diastolic blood pressure of 70 and a maximal heart rate of 130: this person has an estimated improvement of 71 with exercise training, and of 47 with the treatments jointly. Thus, simple exercise is much better psychically.

To conclude, a finc-grain analysis, such as illustrated above, is cogently needed. In all probability, a comparison of group effects leaves out valuable information. Prediction analysis is at least as informative as analysis of treatment effects. Treatment effects can be tested equally well in prediction analysis. The result of this study underlines that the goal of individualized rehabilitation is feasible, rendering rehabilitation more valuable, compared to a standard programme.

\section{REFERENCES}

1. Mayou M. Prediction of emotional and social outcome after a heart attack. J Psychosom Res 1984; 28: $17-25$.

2. Wiklund I, Sanne H, Vedin A, Wilhelmsson C. Psychosocial outcome one year after a first myocardial infarction. J Psychosom Res 1984; 28: 309-321.

3. Philip Ae, Cay AL, Stuckey NA, Vetter NJ. Multiple predictors and multiple outcomes after myocardial infarction. J Psychosom Res 1981; 25: 137-141.

4. Diederiks JPM, Van Der Sluiss H, Weeda HWH, Schobre MG. Predictors of physical activity one year after myocardial infarction. Scand J Rehab Med 1983; 15: 103-107.

5. MAELAND JG, HAviK OE. Psychological predictors for return to work after a myocardial infarction. J Psychosom Res 1987; 31: 471-481.

6. Langosch W. Psychological effects of training in coronary patients: a critical review of the literature. Eur Heart $J$ 1988; 9 (suppl M): 37-42.

7. Uniken Venema-Van Uden MMAT, Zoeteweij MW, Erdman RaM, Van Den Berg GM, Smeets JG, Weeda HWh, Vermeulen A, Van Meurs-Van Woezik H, Ebink C. Medical, social and psychological recovery after cardiac rehabilitation. $J$ Psychosom Res 1989; 33: 651-656. 
8. Van Dixhoorn J, Duivenvoorden IIJ, Pool J, Success and failure of exercise training after myocardial infarction: is the outcome predictable? J Am Coll Card 1990; 15: 974-982.

9. Myers J, Froelicher VF. Predicting outcome in cardiac rehabilitation. JACC 1990; 15: $983-985$.

10. Van Dixhoorn J, Duivenvoorden HJ, Pool J, Verhage F. Psychic effects of physical training and relaxation therapy after myocardial infarction. J Psychosom Res 1990; 34: 327-337.

11. ERdMAN RAM. Welbevinden bij Hartpatienten. Lisse: Swets and Zeitlinger, 1981.

12. Van Der Ploeg H, Defares P, Spielberger C. Handleiding bij de zelf-beoordelings vragenlijst ZBV (STAI-DY). Manual for the State-Trait Anxiety Inventory-DY. Lisse: Swets and Zeitlinger, 1980.

13. Visser P, Hofman WF, Kumar A. Sleep and mood: measuring the sleep quality. In: Sleep Research. (Edited by Priest RG, Pletscher A, Ward J). Lancaster: MTP Press, 1979.

14. Appels A, Dehaes W, Schuurman J. Een test ter meting van het 'coronary prone behaviour pattern' Type A. Ned T Psychologie 1979; 34: 181-188.

15. Appels A, Mulder P. Fatigue and heart disease. The association between 'vital exhaustion' and past, present and future coronary heart disease. J Psychosom Res 1989; 33: 727-738.

16. VAN DixhooRN J. Body Awareness: the proper application of relaxation and breathing technique. Gedrag 1984; 12: 31-45.

17. Van Dixhoorn J, Duivenvoorden HJ, Stanl HA, Pool J. Physical training and relaxation therapy in cardiac rehabilitation assessed through a composite criterion for training outcome. $A m$ Heart J 1989; 118: 545-552.

18. Meyer GC. Cardiovascular Rehabilitation: a discipline in need of a new direction ? $J$ Cardiopul Rehab 1985; 5: 507-509.

19. UniKen Venema- VAN Uden, MMAT. Hartrevalidatie-over het bepalen en voorspellen van herstel. Dissertation, Rotterdam, 1990.

20. Fioretti P, BaArdman T, Brower RW, Hugenholtz PG. Hemodynamic measurements during the acute phase of myocardial infarction: implications for prognosis and cardiac rehabilitation. $J$ Cardiopul Rehab 1988; 8: 265-269.

21. Fioretti P, Simoons ML, Zwiers G, Baardman T, Brower RW, Kazemir M, Hugenholtz PG. Value of predischarge data for the prediction of exercise capacity after cardiac rehabilitation in patients with recent nnocardial infarction. Eur Heart $J$ 1987; 8 Suppl. G: 33-38. 